\title{
Algoritmo de picking automático para dados sísmicos 3D: aplicação em dado real da bacia sedimentar do Recôncavo.
}

\author{
Wilker E. Souza*, CPGG/UFBA, Rafael R. Manenti, CPGG/UFBA, Milton J. Porsani, CPGG/UFBA.
}

Copyright 2019, SBGf - Sociedade Brasileira de Geofísica

This paper was prepared for presentation during the $16^{\text {th }}$ International Congress of the Brazilian Geophysical Society held in Rio de Janeiro, Brazil, 19-22 August 2019.

Contents of this paper were reviewed by the Technical Committee of the $16^{\text {th }}$ International Congress of the Brazilian Geophysical Society and do not necessarily represent any position of the SBGf, its officers or members. Electronic reproduction or storage of any part of this paper for commercial purposes without the written consent of the Brazilian Geophysical Society is prohibited.

\begin{abstract}
Statics correction corresponds to a time-shift which is applied to seismic trace in order to eliminate the reflections misalignment, caused by topography and weathered layer effects. This correction depends on the precise determination of the first breaks. To determine the first breaks on seismogram can be an arduous task if data were acquired in complex regions and with low signal to noise ratio. The picking is performed on normal move-out corrected shot-gathers, turning the refracted events into horizontal events. The first-break picking method is automatic, stable and reliable for the statics correction calculation. We tested the method using shot-gathers from 3D seismic data located in Recôncavo sedimentary basin acquired with explosive source. The proposed method is robust, numerically stable, computationally efficient and easy to apply.
\end{abstract}

\section{Introdução}

As variações da zona de baixa velocidade (ZBV) e topográficas da superfície terrestre fazem com que as distâncias percorridas pelos raios sísmicos refletidos sejam desiguais para diferentes pares fonte-receptor, originando, dessa forma, deslocamentos nos tempos de trânsitos registrados. Estes erros estáticos ocorrem traço a traço e são suficientes para modificar completamente a forma estrutural do refletor em subsuperfície, mapeado na seção sísmica (Cunha, 2010). O cálculo desses tempos são sempre feitos em relação a um nível de referência chamado datum e simulam o efeito do deslocamento da fonte e do receptor para este datum. Dessa forma, a depender do posicionamento do nível de referência, os tempos que representam as estáticas podem ser adicionados ou subtraídos dos traços sísmicos.

Hoje, os métodos mais usados para obtenção das correções estáticas em escala industrial se baseiam na utilização das primeiras quebras dos sismogramas de reflexão. De uma maneira geral, as primeiras quebras de um sismograma de reflexão correspondem à onda direta e refrações críticas. Os sismogramas trazem nos afastamentos curtos informações da velocidade da ZBV, e nos afastamentos mais longos informações da velocidade da subZBV, parâmetros necessários para o cálculo das espessuras das camadas em subsuperfície. Com o uso das primeiras quebras, a quantidade de curvas tempo $\mathrm{x}$ afastamento é muito grande, aumentando a redundância de informações sobre a ZBV. Esta redundância pode ser aproveitada através de algoritmos de inversão por mínimos quadrados, como a tomografia de primeiras quebras (Amorim, 1985).

Tradicionalmente, a determinação do sinal que corresponde à primeira quebra foi realizado através de uma inspeção visual das amplitudes, os picks eram feitos manualmente. Além de ser muito demorado, essa estratégia pode levar a escolhas tendenciosas e inconsistentes, pois, depende da subjetividade de cada profissional. Com o desenvolvimento de computadores modernos, foram criados softwares de picking automáticos, ainda assim, todo o procedimento ainda é muito demorado e subjetivo. Assim, a implementação de novos algoritmos para picking automáticos de forma objetiva e consistente é muito importante. Atualmente, utilizam-se métodos de picking automático como um primeiro passo e os resultados passam por uma inspeção visual. Muitas desses processos têm de ser repetido várias vezes. Quando o volume dos dados é grande e sua qualidade baixa, o processo de picking pode levar de $20 \%$ a $30 \%$ do tempo total do processamento (Sabbione e Velis, 2010).

Métodos relativamente novos, incluem algoritmos baseados em redes neurais (utilizada pelo software comercial ProMax/SeisSpace, por exemplo). Esta abordagem provou ser muito útil para determinação dos picks das primeiras quebras. Porém sem um bom treinamento da rede, os resultados podem exigir vários ajustes manuais que consomem muito tempo, especialmente quando a qualidade do dado é baixa.

Foi proposto por Souza (2016) um algoritmo que melhora significativamente a capacidade de detectar as primeiras quebras em dados sísmicos 2D. Este artigo tem por finalidade apresentar a expansão e atualização do método de picking automático para utilização em dados sísmicos 3D terrestres.

\section{Metodologia}

Na metodologia proposta, o procedimento para picking das primeiras quebras para dados 3D é dividido em cinco fases: a primeira, é a correção de elevação com o intuito de atenuar os efeitos causados pela variação da topografia do terreno; a segunda, calcula-se o atributo envelope, através da transformada de Hilbert, utilizando a parte real e a parte imaginária do traço sísmico; a terceira, utiliza-se a correção de Linear Normal Moveout (LMO) a fim de facilitar a aplicação de filtragens; a quarta é a filtragem SVD, a qual é muito útil na atenuação de ruídos aleatórios e definição da primeira quebra; e por último, a marcação 
dos picks através da razão de energia em cada traço sísmico, em uma região no sismograma pré-definida. A seguir, serão abordadas as cinco fases do método.

\section{Correção de elevação}

O método proposto está programado para atuar no domínio do tiro pelo offset. Como o dado sísmico é proveniente de uma aquisição em 3D, o offset varia de forma radial a partir do ponto de tiro. Dessa forma, as variações topográficas são acentuadas pois neste domínio, os traços que possuem offsets próximos são colocados lado a lado, entretanto, suas posições (coordenadas $\mathrm{X}, \mathrm{Y}$ ) pode estar distantes um dos outros. Nesse contexto, as variações de topografia está bem mais acentuada, pois traços vizinhos podem ter variações bruscas de elevação. Sendo assim, os traços são fortemente influenciados pela topografia e perdem 0 caráter linear das ondas diretas e refratadas. A correção de elevação é utilizada com o intuito de atenuar esses efeitos.

A Figura 1 ilustra dois domínios de organização dos dados sísmicos. Na Figura 1 a) o dado é organizado no domínio do tiro pelo canal e a Figura 1 b), o dado é organizado no domínio do tiro pelo offset. Observa-se que as variações de elevação são mais bruscas no exemplo b), influenciando no tempo de registro das primeiras quebras. Assim, faz-se necessário a utilização da correção de elevação para melhor atuação das etapas posteriores do método.

O cálculo do tempo, $t_{i}$, para a correção é feito utilizando a elevação dos traços do dado sísmico, $x_{i}$, e uma velocidade média do terreno $v$ (utiliza-se em média a velocidade da ZBV).

$$
t_{i}=\frac{x_{i}}{v}
$$

Em seguida, é feito uma normalização com relação ao maior valor da correção calculado anteriormente (quanto maior a elevação do receptor no qual foi coletado o traço, maior será o valor da correção). Considere $\operatorname{Max}_{i}$ como sendo o maior valor da correção calculado anteriormente e como sendo $\mathrm{Val}_{i}$ os demais valores calculados na correção. O valor a ser corrigido normalizado, $t N o r_{i}$ será de:

$$
t \text { Nor }_{i}=\operatorname{Max}_{i}-\mathrm{Val}_{i}
$$

O tempo normalizado calculado (em segundos) é convertido para milissegundos e posteriormente para amostra (de acordo com a amostragem do dado). O próximo passo é adicionar as informações, que são armazenadas em uma tabela .txt no header de cada traço. A Figura 2 mostra o dado antes, a), e após, b), a correção de elevação. Após a conclusão das etapas seguintes, a correção de elevação é subtraída da tabela de pick com o intuito de reposicioná-los nas localizações corretas.

Transformada de Hilbert e Envelope
Considere $x(t)$ o traço sísmico real e $y(t)$ a transformada de Hilbert de $x(t)$. Quando os traços são somados, o resultado é o traço sísmico complexo $Z(t)$ (curva helicoidal), sendo definido por:

$$
Z(t)=x(t)+i y(t)
$$

A parte imaginária, $y(t)$, também denominada de quadratura ou conjugado e $Z(t)$ podem ser determinados unicamente em termos da Transformada de Hilbert ou então por convolução no domínio do tempo, usando-se o operador de quadratura associado à transformada de Hilbert. "O sinal analítico não contém componentes de frequências negativas", podendo ser obtido a partir do sinal real pela supressão das frequências negativas (Bracewell, 1965 e Claerbout, 1976). Estas técnicas baseiam-se na observação de que 0 espectro de amplitude do traço complexo desaparece para $\omega<0$ e tem 2 vezes a magnitude para $\omega>0$. Como a fase mantém-se constante (exceto quando ela não é definida para $\omega<0$ ) o traço complexo pode então ser estimado da seguinte forma: (1) transformada de Fourier do traço real; (2) Zerando-se as amplitudes para as frequências negativas e dobrando-se as amplitudes das frequências positivas, e (3) transformada inversa de Fourier (Mojica et al, 2011).

O envelope $A(t)$ pode ser calculado representando a amplitude do traço sísmico complexo naquele ponto. A amplitude instantânea é uma função positiva, o que significa que seu valor numérico é sempre positivo. Matematicamente, esta amplitude é calculada como:

$$
A(t)=\sqrt{x^{2}(t)+y^{2}(t)}
$$

Correção de linear moveout (LMO)

As primeiras quebras (ondas diretas e refratadas), por exemplo, muitas vezes podem ser representadas como uma linha reta, ou bem próximo disso. A correção LMO é uma projeção desses eventos na horizontal, eliminando o efeito do afastamento offset no tempo de percurso, removendo o mergulho da primeira quebra dos sismogramas. Para isso, numa primeira etapa é avaliada a velocidade média da refração de primeira quebra ao longo da linha. Definida a velocidade média do primeiro refrator, é aplicada uma correção de LMO para cada registro. A correção individual do traço se baseia na distância entre seu tiro e seu receptor.

\section{Filtragem SVD}

Seguindo o procedimento proposto por Porsani et al. (2009), consideramos um conjunto de dados sísmicos $d\left(t, x_{n}\right)$, onde o eixo do tempo é dado pelo número de amostra, $t=1,2, \ldots, N_{t}$ e o eixo do espaço é dado pela posição relativa $x_{n}, n=1,2, \ldots, N_{x}$. . As reflexões primárias foram corrigidas de LMO, de modo que estejam alinhadas horizontalmente na direção $x$. Uma janela com $2 M+1$ traços centrado em $x_{n}$ é dado por uma matriz de componentes $d\left(t, x_{n+j}\right), t=1, \ldots, N_{t}, j=-M, \ldots, 0, \ldots, M$. 
Esta definição pode ser representado pelo SVD reduzido (Golub e van Loan, 1996).

$$
d\left(t, x_{n}\right)=\sum_{k=1}^{2 M+1} \sigma_{k} u_{k}(t) v_{k}(j)
$$

Os valores singulares são organizados de forma decrescente $\sigma_{1} \geq \sigma_{2} \geq \cdots \geq \sigma_{2 M+1} \geq 0$. O dado filtrado é definido apenas pelas primeiras autoimagens $K$ do traço central.

$$
\left(t, X_{n}\right)=\sum_{k=1}^{K} \sigma_{k} u_{k}(t) v_{k}(0)
$$

O procedimento é iniciado em $n=M+1$, onde a saída filtrada é a soma das $K$ autoimagens correspondentes aos $K$ maiores valores singulares dos primeiros traços $M+1$.

$$
\left(t, X_{M+1+j}\right)=\sum_{k=1}^{K} \sigma_{k} u_{k}(t) v_{k}(j), j=-M, \ldots, 0
$$

Os dados de saída são formados pela soma das primeiras 7 autoimagens, isso é:

$$
\left(t, X_{N_{x}-M+j}\right)=\sum_{k=1}^{K} \sigma_{k} u_{k}(t) v_{k}(j), j=0, \ldots, M
$$

O resultado do dado filtrado, $\breve{d}\left(t, x_{n}\right)$, é formado através dos $K$ autovetores. Se utilizarmos valores pequenos de $K$, as seções e os traços resultantes possuirão maior coerência espacial, preservando eventos horizontais e sub-horizontais, e atenuando os eventos aleatórios e mais verticais (Porsani et al, 2009 e Mojica et al, 2011). Esse fato é válido pois os sismogramas estão corrigidos de LMO. Dessa forma, as primeiras quebras passam de eventos lineares inclinados para eventos lineares horizontais, alinhadas com 0 eixo $\mathrm{X}$, aumentando a eficiência da filtragem.

\section{Definição dos picks}

A definição dos picks é realizada com base na energia do envelope, de acordo com as etapas a seguir:

- Cálculo da energia total do envelope, $E=\sum_{i=1}^{N} X_{i}$, em que $N$ é o número total de amostras e $X_{i}$ é a amplitude;

- Definição do fator de tolerância $\varepsilon$, que indica a porcentagem da energia total do envelope, $\varepsilon=$ $n . E$. Neste caso, $n$ é a porcentagem da energia do envelope que corresponde ao local aonde o pick será definido;

- A definição do pick será efetuado na amostra quando $\varepsilon=n$. $E$ ou, quando $\varepsilon>n$. $E$, o algoritmo considerará como pick a amostra anterior.

Após a definição dos picks, é aplicado a correção de LMO inversa (utiliza-se neste caso, a mesma velocidade aplicada na correção de LMO) e a correção e elevação inversa, a fim de posicionar os picks nas correspondentes primeiras quebras do sismograma de reflexão.

Devido às filtragens e o modelo de definição dos picks (através da soma da energia de cada amostra em uma região pré definida, em cada traço), os picks não são posicionados nas amostras que contemplem as maiores amplitudes da primeira quebra, e sim nas proximidades. A fim de posicionar os picks nas amostras que contemplem as maiores energias, é feito uma última iteração. No dado original, sem filtragens, os picks são posicionados em suas respectivas amostras e é definida uma janela com $\mathrm{N}$ amostras acima e abaixo do picking calculado pelo método. O algoritmo, nessa janela, procura a amostra de maior energia e redefine o pick, que são salvos em uma tabela txt e no header de cada traço.

\section{Resultados}

Com o objetivo de confirmar a eficácia do método de picking automático para dados sísmicos 3D, foi escolhido o dado sísmico 3D de Polo Miranga, proveniente da bacia sedimentar do Recôncavo. As informações sobre a geometria de campo podem serem vistas na Tabela 1:

\begin{tabular}{cc}
\hline Parametros de aquisição & Reflection \\
\hline Intervalo de Receptores & $40(\mathrm{~m})$ \\
Intervalo de fontes & $40(\mathrm{~m})$ \\
Intervalo entre linas de receptor & 240 \\
Intervalo entre linhas de tiro & $240(\mathrm{~m})$ \\
Offset mínimo & $20(\mathrm{~m})$ \\
Offset máximo & $4060(\mathrm{~m})$ \\
Tempo de registro & $5(\mathrm{~s})$ \\
Razão de amostragem & $2(\mathrm{~ms})$ \\
Tipo de fonte & Dinamite \\
Quantidade de tiros & 24618 \\
\hline
\end{tabular}

Tabela 1: Tabela com a informação dos parâmetros de aquisição do cubo sísmico de Polo-Miranga.

De um modo geral, a qualidade da primeira quebra está relacionada com as condições próxima à superfície, com o tipo de fonte e a relação sinal/ruído. A Figura 3 ilustra o passo a passo do método proposto para picking automático em dados 3D. A Figura 4 (a) ilustra uma linha de receptor de um tiro, em (b) a definição dos pick na primeira quebra do dado e em (c) o dado sísmico após a correção estática. Não faz-se necessário calcular os picking para todos os offsets do dado. Para este exemplo foi limitado o cálculo da correção estática até o offset de $1500 \mathrm{~m}$.

\section{Conclusões}

O método de picking automático para dados sísmicos 3D foi aplicado no cubo sísmico de Polo Miranga, proveniente da bacia sedimentar do Recôncavo. O domínio do offset foi adotado para a aplicação do método. Percebe-se que a variação topográfica para este domínio é mais acentuado pois traços vizinhos podem ter variações bruscas de elevação. Sendo assim, os traços são 
fortemente influenciados pela topografia e perdem o caráter linear das ondas diretas e refratadas. Dessa forma, a aplicação da correção de elevação foi fundamental para o sucesso do método. O método proposto é robusto para dados ruidosos e forneceram picks consistentes. No geral, foi observado que o método é eficaz para a determinação das primeiras quebras em dados sísmicos 3D que se caracterizam por uma chegada forte de energia.

\section{Agradecimentos}

Agradecemos ao fomento à pesquisa dado pelo CNPq/INCT-GP/FAPESP,PETROBRAS/ANP e FINEP (Projeto GASBRAS); a Landmark pela licença do pacote de dados ProMAX/SeisSpace e ao LAGEP/CPGG pela viabilização de suas instalações físicas usadas para produção do artigo.

\section{Referências}

Amorim, W. N. 1985. Cálculo das correções estáticas através do princípio da tomografia sísmica, Tese de doutorado, Universidade Federal Da Bahia, Salvador, Brasil.

Bracewell, R. N. 1965. The Fourier transform and its application, Mc Graw-Hill, New York.
Claerbout, J. 1976. Fundamentals of geophysical data processing with aplications to petroleum prospecting, Mc Graw-Hill, New York.

Cunha, R. S. 2010. Cálculo das correções estáticas, Trabalho de graduação, Universidade Federal Da Bahia, Salvador, Brasil.

Golub, G. H \& Van Loan, C. F. 1996. Matrix Computations. 3 ed. (Baltimore: Johns Hopkins University Press). Matrix computations: Johns, $694 \mathrm{p}$.

Mojica, O. F. \& Porsani, M. J. \& Silva, M. G. 2011. Aplicações da filtragem svd na análise de velocidades e no empilhamento CMP, Resumo Expandido CisBGf.

Porsani, M. J. \& Silva, M. G. \& Melo, P. E. M. \& Ursin, B. 2009. Ground-roll attenuation based on svd Flltering, SEG Expanded Abstracts, 28:3381-3385

Sabbione, J. I. \& Velis, D. 2010. Automatic first-breaks picking: New strategies and algorithms, Geophysics, 75:67-76.

Souza, W. E. 2016. Determinação automática das primeiras quebras e aplicações na correção estática e processamento sísmico da Bacia do Parnaíba, Dissertação de Mestrado, Universidade Federal da Bahia, Salvador, Brasil.

a)
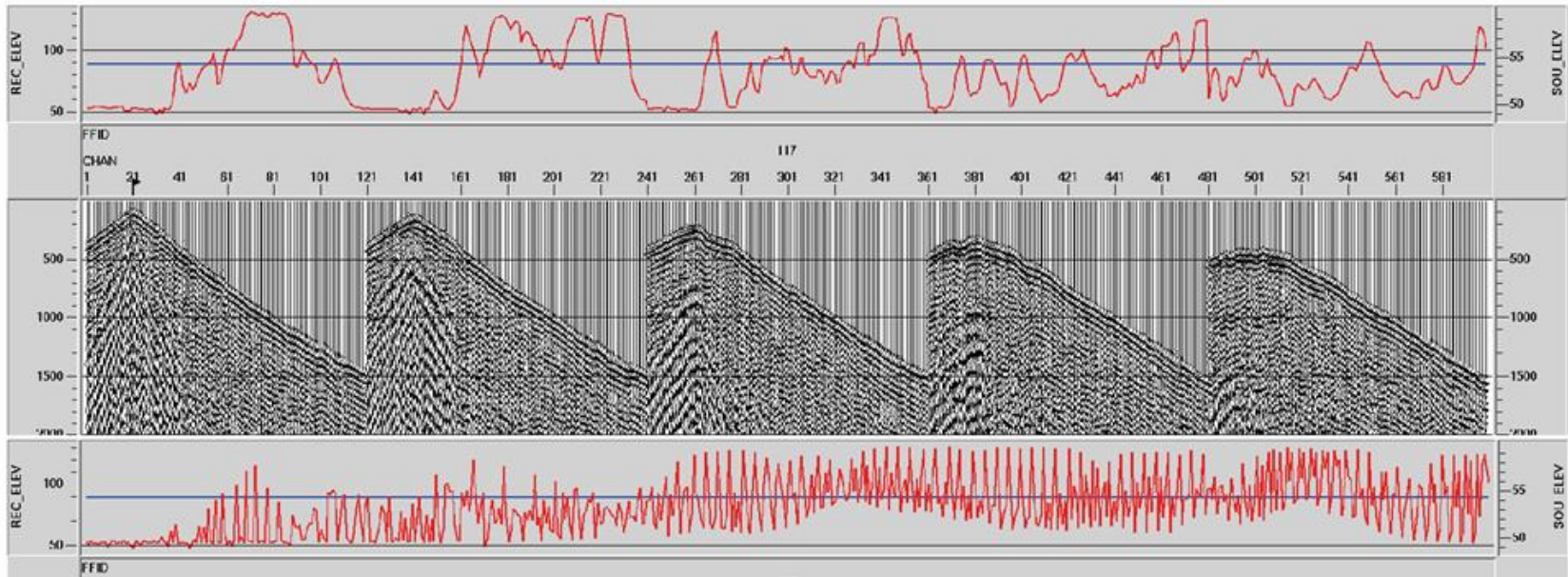

b)

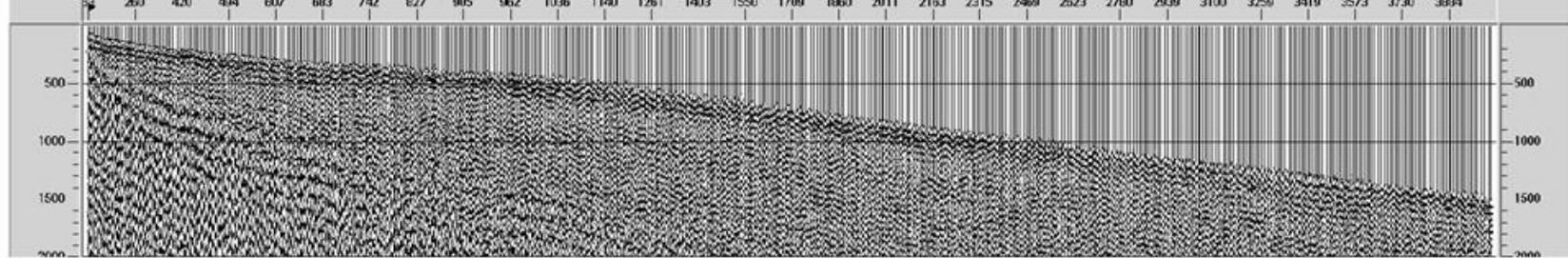

Figura 1: Em a), dado organizado no domínio do tiro pelo canal, observa-se para este exemplo que cinco linhas de tiros estão ligadas. Em b), o dado está organizado no domínio do tiro pelo offset. Observa-se que as variações de elevação são mais bruscas no exemplo b). Observar a variação da elevação dos receptores em vermelho. 


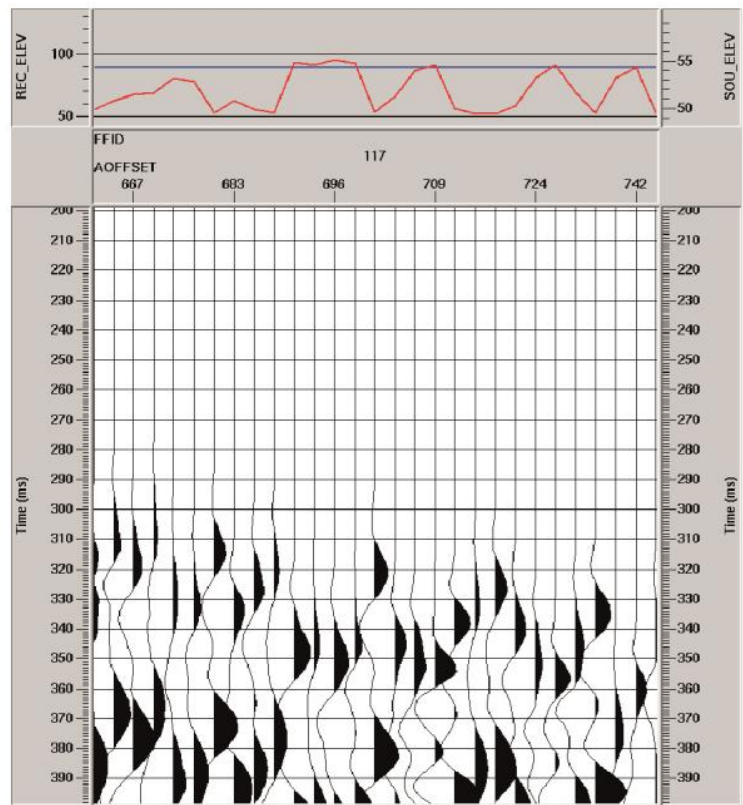

a)

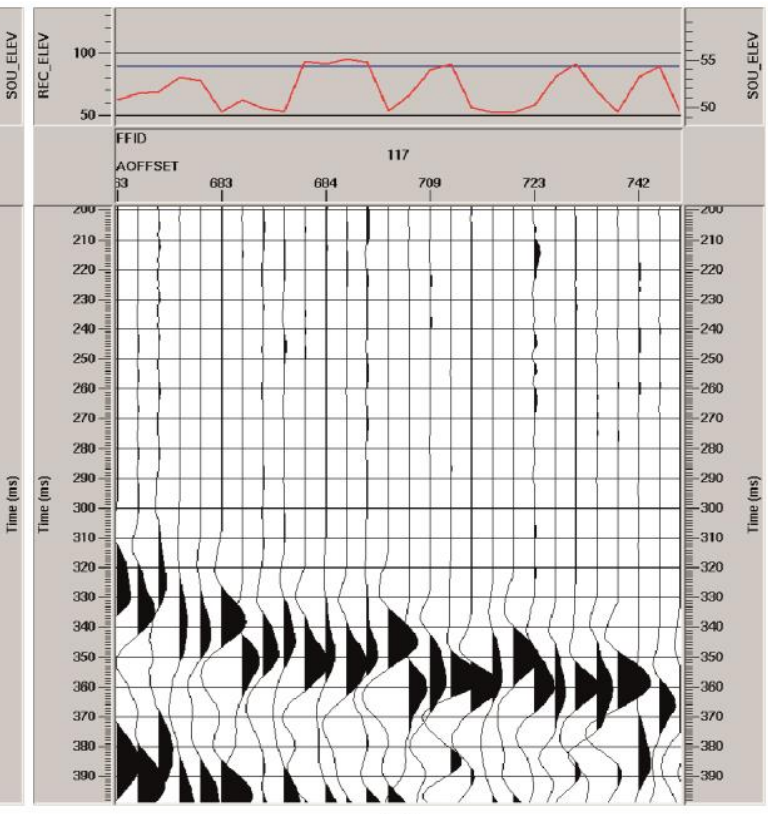

b)

Figura 2: Dado sísmico antes, a), e após, b), a correção de elevação. Observar a variação da elevação dos receptores em vermelho.

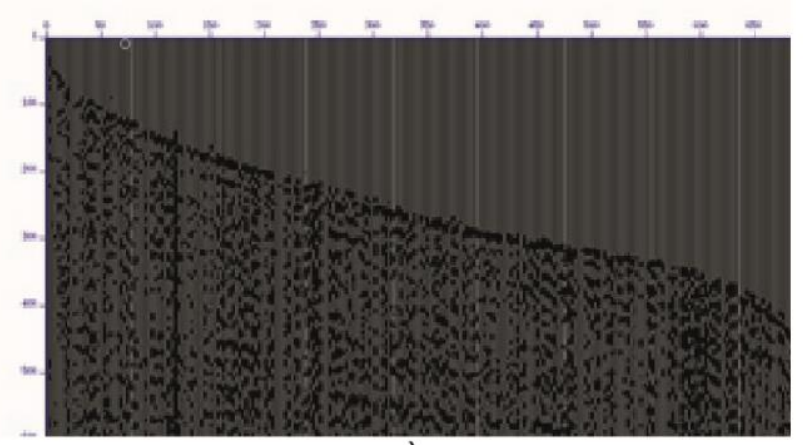

a)

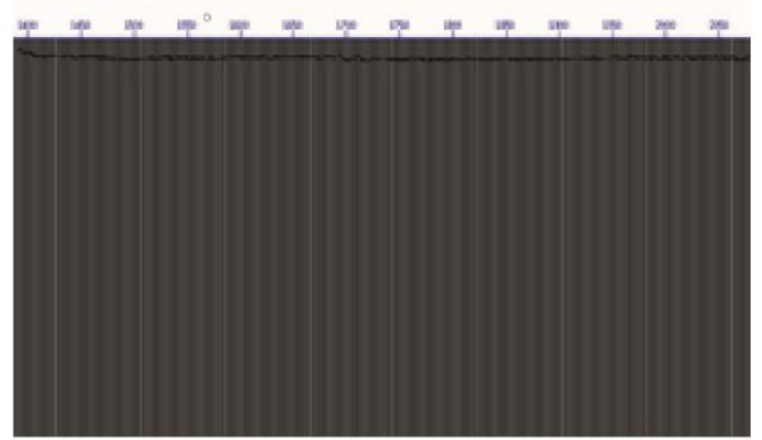

C)

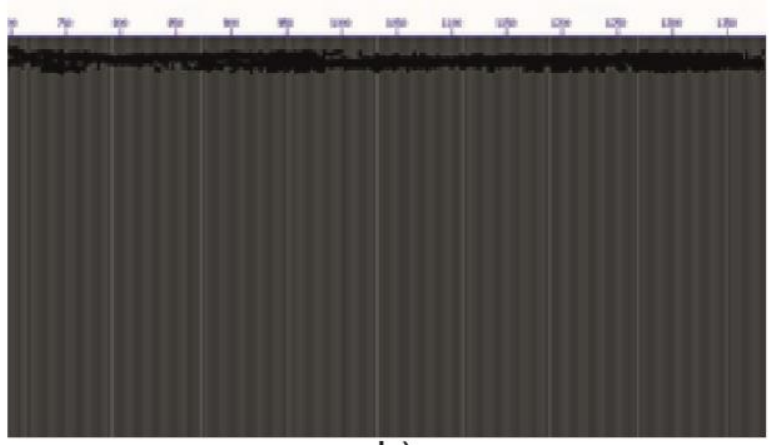

b)

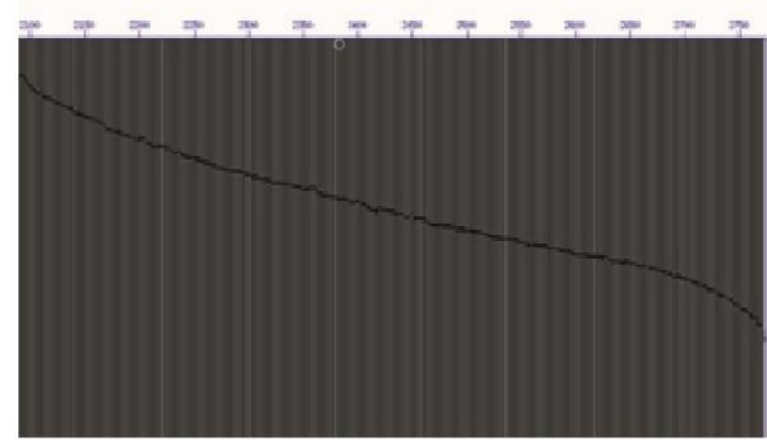

d)

Figura 3: Etapas do algoritmo de picking automático: a) envelope, b) correção de LMO e filtrado com SVD, c) determinação dos picks e d) LMO inverso. 


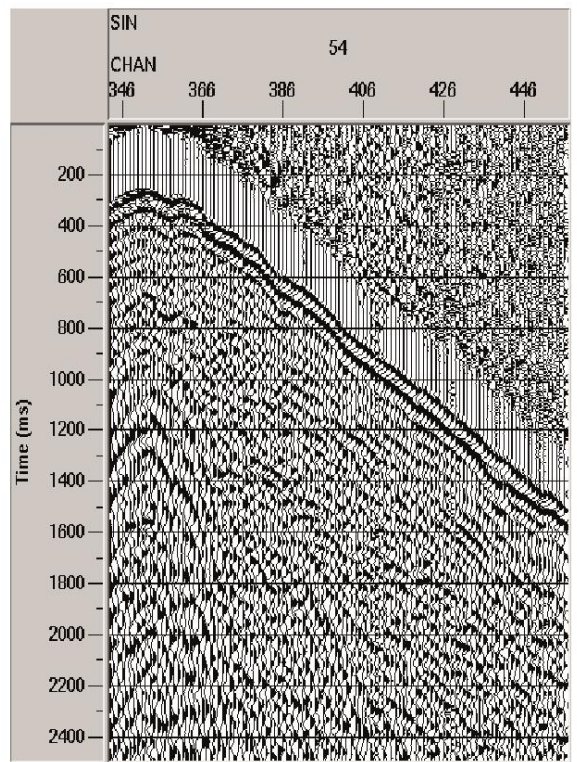

a)

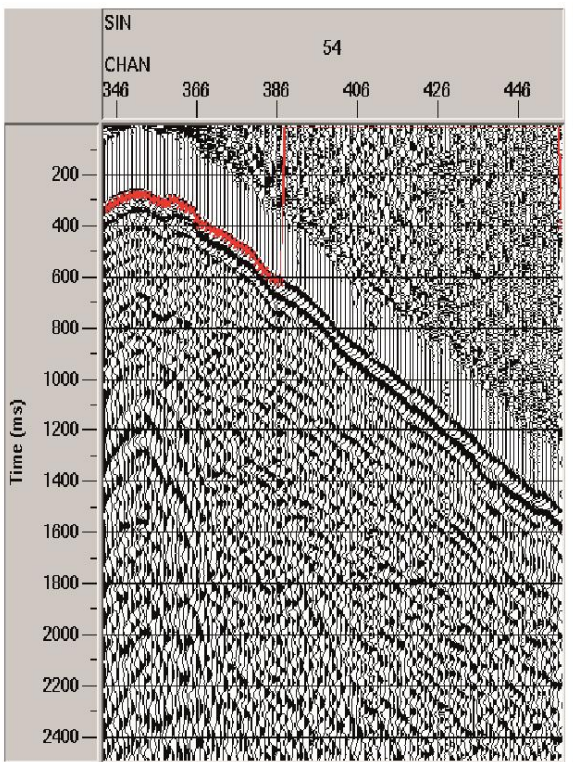

b)

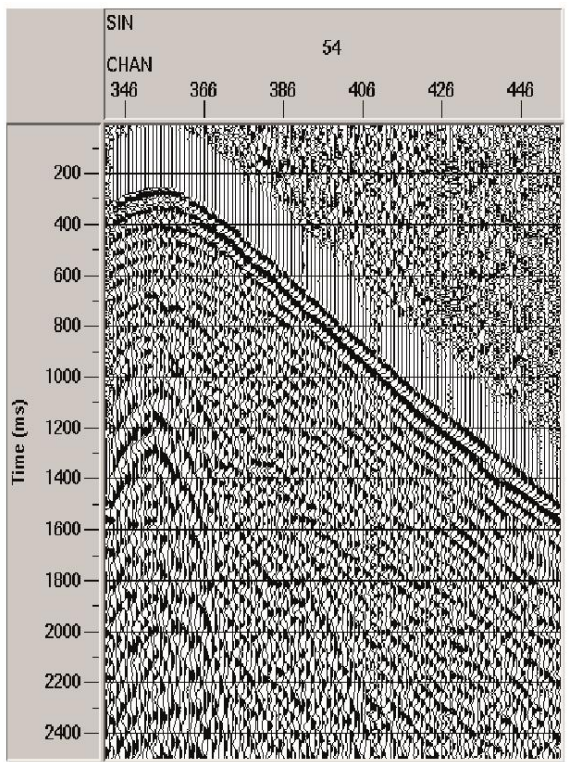

c)

Figura 4: (a) ilustra uma linha de receptor de um tiro, em (b) a definição dos picks na primeira quebra do dado e em (c) o dado sísmico após a correção estática. 